STUDI

FRANCESI

\section{Studi Francesi}

Rivista quadrimestrale fondata da Franco Simone

143 (XLVIII | II) | 2004

Varia - fasc. II - maggio-agosto 2004

\title{
I vangeli delle filatrici, a cura di Daniela Musso
}

\section{Walter Meliga}

\section{(2) OpenEdition}

\section{Journals}

\section{Edizione digitale}

URL: https://journals.openedition.org/studifrancesi/39036

DOI: 10.4000/studifrancesi.39036

ISSN: 2427-5856

\section{Editore}

Rosenberg \& Sellier

\section{Edizione cartacea}

Data di pubblicazione: 1 décembre 2004

Paginazione: 343

ISSN: 0039-2944

\section{Notizia bibliografica digitale}

Walter Meliga, «I vangeli delle filatrici, a cura di Daniela Musso», Studi Francesi [Online], 143 (XLVIII | II) | 2004, online dal 30 novembre 2015, consultato il 19 mai 2021. URL: http://journals.openedition.org/ studifrancesi/39036 ; DOI: https://doi.org/10.4000/studifrancesi.39036

Questo documento è stato generato automaticamente il 19 mai 2021.

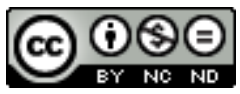

Studi Francesi è distribuita con Licenza Creative Commons Attribuzione - Non commerciale - Non opere derivate 4.0 Internazionale. 


\section{I vangeli delle filatrici, a cura di Daniela Musso}

Walter Meliga

NOTIZIA

I vangeli delle filatrici, a cura di DANIELA Musso, Alessandria, Edizioni dell'Orso, 2001, pp. 183 («Gli Orsatti. Testi dell’Altro Medioevo», 12).

1 Riedizione con traduzione italiana dei cosiddetti Evangiles des quenouilles (testo anonimo della fine del sec. XV), secondo il testo dell'edizione di Madeleine Jeay (Les Evangiles des Quenouilles, Montréal, Les Presses de l'Université de Montréal, 1985). La riedizione è accompagnata da un'ampia e articolata introduzione sui contenuti e sulle valenze culturali dell'opera nonché sui diversi livelli di lettura che essa consente (satira antifemminile, repertorio di credenze popolari, documento di costume della Francia del Nord e delle Fiandre nel XV secolo, testo «carnevalesco»). 